Original Article

\title{
Effects of deep breathing on internal oblique and multifidus muscle activity in three sitting postures
}

\author{
Min-Joo Ko, PT, MS ${ }^{1)}$, Eun-Joo Jung, BHSc ${ }^{2)}$, Moon-Hwan Kim, PT ${ }^{3)}$, \\ JAE-SEOP OH, PT, $\left.\mathrm{PhD}^{4}\right)^{*}$ \\ 1) Department of Rehabilitation Science, Graduate School, Inje University, Republic of Korea \\ 2) Department of Physical Therapy, Graduate School, Inje University, Republic of Korea \\ 3) Department of Rehabilitation Medicine, Wonju Severance Christian Hospital, Republic of Korea \\ 4) Department of Physical Therapy, College of Biomedical Science and Engineering, Inje University: \\ 607 Obang-dong, Gimhae-si, Gyeongsangnam-do 621-749, Republic of Korea
}

\begin{abstract}
Purpose] This study was to investigate differences in the level of activity of the external oblique (EO), internal oblique (IO), and multifidus (MF) muscles with deep breathing in three sitting postures. [Subjects and Methods] Sixteen healthy women were recruited. The muscle activity (EO, IO, MF) of all subjects was measured in three sitting postures (slumped, thoracic upright, and lumbo-pelvic upright sitting postures) using surface electromyography. The activity of the same muscles was then remeasured in the three sitting postures during deep breathing. [Results] Deep breathing significantly increased activity in the EO, IO, and MF compared with normal breathing. Comparing postures, the activity of the MF and IO muscles was highest in the lumbo-pelvic upright sitting posture. [Conclusion] An lumbo-pelvic upright sitting posture with deep breathing could increase IO and MF muscle activity, thus improving lumbo-pelvic region stability.

Key words: Deep breathing, Multifidus, Sitting posture
\end{abstract}

(This article was submitted Nov. 21, 2017, and was accepted Jan. 9, 2018)

\section{INTRODUCTION}

Significant changes in trunk muscle activation occur with changes in the thoracolumbar sitting posture ${ }^{1)}$. A slumped sitting posture relies on passive lumbo-pelvic structures to maintain an upright position against gravity. As a result, the requirement for muscle activity is reduced. Clinically, such passive postures frequently exacerbate low back pain (LBP). The optimal sitting posture involves a more neutral spine position, with slight lumbar lordosis and a relaxed thorax ${ }^{2}$. Many believe that local muscles, such as the multifidus (MF) and internal oblique (IO), are crucial for sitting posture; they function primarily as stabilizers and have multi-segmental effects ${ }^{3)}$.

The abdominal muscles play a role in expiration ${ }^{4}$. Generally, no abdominal muscle activity is observed during respiration at rest, while abdominals are activated during expiratory effort ${ }^{5)}$. Maximum expiration is a training method for co-activation of the lateral abdominal muscles ${ }^{6}$. The abdominal muscles also provide trunk stability during deep breathing ${ }^{7)}$. Therefore, the purpose of this study was to compare the changes of MF, IO and exteranl oblique (EO) muscles according to deep breathing in three sitting postures.

*Corresponding author. Jae-Seop Oh (E-mail: ysrehab@inje.ac.kr)

(C2018 The Society of Physical Therapy Science. Published by IPEC Inc.

(c) (1) $\odot$ This is an open-access article distributed under the terms of the Creative Commons Attribution Non-Commercial No Deriva-

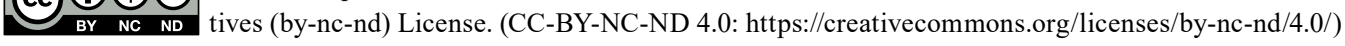




\section{SUBJECTS AND METHODS}

This study enrolled 16 healthy females (mean age, $34.1 \pm 13.1$ years; mean height, $161.0 \pm 4.2 \mathrm{~cm}$; mean weight, 53.3 $\pm 6.0 \mathrm{~kg}$ ). Potential subjects who had a history of lumbar spine surgery or difficulty maintaining the sitting postures were excluded from the study. All participants signed an informed consent form, approved by the Institutional Review Board of Inje University (approval No: INJE 2016-10-052-001), before participating in this study.

The Trigno wireless EMG system (Delsys, Inc., Boston, MA, USA) was used to measure the electromyography (EMG) activity of the IO, EO, and MF muscles bilaterally. The sampling rate was $1,000 \mathrm{~Hz}$, with a $20-450 \mathrm{~Hz}$ bandpass filter. All raw EMG data were converted into root mean square data for the analysis. The electrodes for the IO, EO, and MF were placed according to Criswell ${ }^{8)}$. The site for each electrode was shaved and then cleaned with alcohol and cotton to reduce skin impedance. To normalize the EMG activity of the IO, EO and MF muscles, the maximum voluntary isometric contraction (MVIC) of these muscles was measured using maneuvers suggested previously).

The muscle activity (EO, IO, MF) of all subjects was measured in three sitting postures (slumped, thoracic upright, and lumbo-pelvic upright sitting) using surface EMG. The activity of the same muscles was then remeasured in the three sitting postures during deep breathing. The deep breathing was performed with "almost maximal effort, which is equivalent to a rating of 10 on the Borg scale". Each sitting posture was held for $5 \mathrm{~s}$ and repeated three times, with a 1-min rest between trials. The average value of the middle $3 \mathrm{~s}$ of the test trials was used for the data analysis.

Differences in IO, EO, and MF EMG activity among conditions were analyzed using two-way repeated-measures analysis of variance with the Bonferroni correction. PASW Statistics software (ver. 18.0; SPSS Inc., Chicago, IL, USA) was used for the statistical analyses. The level of statistical significance was set at 0.05 .

\section{RESULTS}

Regarding the activity of the EO $(\mathrm{F}=2.385, \mathrm{p}=0.109)$, IO $(\mathrm{F}=1.356, \mathrm{p}=0.290)$, and $\mathrm{MF}(\mathrm{F}=0.160, \mathrm{p}=0.853)$, there was no interaction between breathing pattern and position $(\mathrm{F}=0.830, \mathrm{p}=0.449)$. However, there were significant main effects of breathing method (EO: $\mathrm{F}=15.465, \mathrm{p}=0.001 ; \mathrm{IO}: \mathrm{F}=31.321, \mathrm{p}<0.000 ; \mathrm{MF}$ : $\mathrm{F}=38.960, \mathrm{p}<0.000)$ and position (IO: $\mathrm{F}=11.137$, $\mathrm{p}=0.001 ; \mathrm{MF}: \mathrm{F}=15.026, \mathrm{p}<0.000)$.

Comparing the sitting postures, the activity of the MF $(p=0.001)$ and $\mathrm{IO}(\mathrm{p}=0.001)$ muscles increased significantly during lumbo-pelvic upright sitting compared with thoracic upright sitting. In comparison of posture, there was no comparison between slump sitting and thoracic upright sitting posture of MF $(p=1.000)$ and IO $(p=1.000)$ muscle activities. The activity of the MF also increased significantly $(\mathrm{p}=0.003)$ during lumbo-pelvic upright sitting compared with slumped sitting.

\section{DISCUSSION}

This study found that deep breathing produced significantly greater activity in the EO, IO, and MF muscles than normal breathing. Comparing the sitting postures, lumbo-pelvic upright sitting was associated with significantly greater activity of the IO and MF muscles than thoracic upright sitting.

Generally, no abdominal muscle activity is observed during respiration at rest. However, the abdominals are activated during expiratory effort ${ }^{5}$. Our results suggest that deep breathing affects the EO, IO, and MF muscles, which maintain an upright position during sitting. O'Sullivan et al. reported that an lumbo-pelvic upright sitting posture results in tonic activity in the IO and $\mathrm{MF}^{2}$. The lumbar-stabilizing muscles are mainly composed of type I fibers and only relatively low loads (approximately $30-40 \%$ MVIC) are needed to improve their performance ${ }^{9}$. In this study, the activity of the MF and IO was $31.52 \%$ and 29.62\% MVIC, respectively, during lumbo-pelvic upright sitting with deep breathing. Anterior pelvic rotation with neutral lumbar lordosis results in activation of the MF and IO. The MF helps to control the extension moment of the lumbar region and the IO restrains the pelvic position against hip extensor momentum ${ }^{10}$. Consequently, lumbo-pelvic upright sitting with deep breathing could be beneficial to increase MF and IO activity and promote lumbo-pelvic region stability.

The lumbo-pelvic upright sitting with deep breathing also may have implications to enhance local muscle activities for lumbo-pelvic stabilization and to prevent lower back pain occurred by prolonged sitting.

The present study had several limitations. First, it is difficult to generalize our findings to other populations because only healthy women were recruited for this study. Second, lumbar lordosis was not quantified in this study. Third, none of the participants had a history of LBP. Future studies are needed to examine the effects of deep breathing in patients with LBP.

\section{Conflict of interest}

None. 


\section{REFERENCES}

1) O'Sullivan PB, Grahamslaw KM, Kendell M, et al.: The effect of different standing and sitting postures on trunk muscle activity in a pain-free population. Spine, 2002, 27: 1238-1244. [Medline] [CrossRef]

2) O'Sullivan PB, Dankaerts W, Burnett AF, et al.: Effect of different upright sitting postures on spinal-pelvic curvature and trunk muscle activation in a pain-free population. Spine, 2006, 31: E707-E712. [Medline] [CrossRef]

3) Bergmark A: Stability of the lumbar spine. A study in mechanical engineering. Acta Orthop Scand Suppl, 1989, 230: 1-54. [Medline] [CrossRef]

4) Hodges PW, Gandevia SC: Changes in intra-abdominal pressure during postural and respiratory activation of the human diaphragm. J Appl Physiol 2000, 89: 967-976. [Medline] [CrossRef]

5) Kera T, Maruyama H: The effect of posture on respiratory activity of the abdominal muscles. J Physiol Anthropol Appl Human Sci, 2005, 24: 259-265. [Medline] [CrossRef]

6) Ishida H, Hirose R, Watanabe S: Comparison of changes in the contraction of the lateral abdominal muscles between the abdominal drawing-in maneuver and breathe held at the maximum expiratory level. Man Ther, 2012, 17: 427-431. [Medline] [CrossRef]

7) Hodges PW, Sapsford R, Pengel LH: Postural and respiratory functions of the pelvic floor muscles. Neurourol Urodyn, 2007, 26: 362-371. [Medline] [CrossRef]

8) Criswell E: Introduction to surface electromyography, 2nd ed. Sudbury: Jones and Bartlett Publishers, 2010.

9) Wilke HJ, Wolf S, Claes LE, et al.: Stability increase of the lumbar spine with different muscle groups. A biomechanical in vitro study. Spine, 1995, 20: 192-198. [Medline] [CrossRef]

10) Queiroz BC, Cagliari MF, Amorim CF, et al.: Muscle activation during four Pilates core stability exercises in quadruped position. Arch Phys Med Rehabil, 2010, 91: 86-92. [Medline] [CrossRef] 